\title{
A Cross Section Study on Type 2 Diabetes Mellitus among Organophosphate Pesticide Applicators in Selected Rural South India
}

\author{
S. Jothi Lakshmi', Santu Ghosh ${ }^{5}$, Padmavathi Ramaswamy ${ }^{2}$, Shriraam Mahadevan ${ }^{3}$ and \\ Krishnendu Mukhopadhya ${ }^{4 *}$ \\ ${ }^{1}$ Faculty of Public Health, Department of Environmental Health Engineering, Sri Ramachandra Institute of Higher \\ Education and Research (Deemed to be University), Chennai - 600116, Tamil Nadu, India; \\ jothilakshmipest25@gmail.com \\ 2Department of Physiology, Sri Ramachandra Institute of Higher Education and Research (Deemed to be \\ University), Chennai -600116, Tamil Nadu, India; Padmavathi.dr@gmail.com \\ ${ }^{3}$ Department of Endocrinology, Sri Ramachandra Institute of Higher Education and Research (Deemed to be \\ University), Chennai -600116, Tamil Nadu, India; mshriraam@gmail.com \\ ${ }^{4}$ Department of Environmental Health Engineering, Sri Ramachandra Institute of Higher Education and Research \\ (Deemed to be University), Chennai - 600116, Tamil Nadu, India; krishnendu@ehe.org.in \\ ${ }^{5}$ Department of Biostatistics, St John's Medical College, Bangalore - 560034, Karnataka, India; \\ santu.biostat@gmail.com
}

\begin{abstract}
Introduction: Diabetes mellitus is one of the metabolic disorders that have multi-factorial pathogenesis. Diabetes is a chief public health issue being suffered by 415 million adults (aged 20-79 years) worldwide as evidenced in 2015. Evidence from the studies recommends that environmental contaminants including insecticides might play a significant role in diabetic pathogenesis. The present study aims to evaluate the relation between OP applicators and incidence of type 2 diabetes mellitus (T2DM). Methods: The study was conducted in 19 rural health centers of Theni District, Tamil Nadu in India. A total of 102 pesticide applicators were recruited for the study. History of occupational pesticide applicators was collected by using questionnaires and HbA1c levels $(>6.5 \%)$ in pesticide applicators were confirmed as diabetic. Result: Among the pesticide applicators, the prevalence of diabetes was found to be $39(38.24 \%)$ among pesticide applicators and only $9(10.47 \%)$ were found to have the family history of diabetes. Risk factors including blood pressure, smoking habit and alcohol drinking were found to be noticeably high with 34 (33.33\%), 59 (57.84\%), 45 (44.12\%), respectively. Conclusion: Our study revealed that the prevalence of diabetes among OP pesticide applicators was higher. The findings of the present study may attract the policymakers to develop a control mechanism against the pesticide-exposed rural population. The variance is deliberated to be explainable by the subject discrepancy regarding safety practices, health background, and nutritional status.
\end{abstract}

Keywords: Diabetes Mellitus, Occupation, Organophosphate, Pesticide Applicators

\section{Introduction}

Diabetes is characterized by abnormal glucose metabolism, featured by decreased insulin production. In type 2 diabetes mellitus (T2DM) reduced sensitivity to the special effects of insulin was observed ${ }^{1}$. The prevalence of diabetes in India was estimated and it was found to be 62 million and more people are diagnosed with diabetes ${ }^{2}$.

*Author for correspondence 
Diabetes is caused by multiple- risk factors like genetic factor ${ }^{3}$ lifestyle and diet ${ }^{4}$ physical activity ${ }^{5}$, obesity ${ }^{\underline{6}}$ and environmental factor ${ }^{7}$. Current studies have recommended that chemical exposures may also contribute to T2DM peril Organophosphates (OPs) impair glucose metabolism in animal models and can lead to hyperglycemia ${ }^{8}$. The study aims to examine the prevalence of T2DM among OP pesticide applicators in selected rural South Indian population. OP pesticides inhibit both serum and erythrocyte cholinesterase ${ }^{9}$. Poisoning can occur through inhalation, dermal, and gastrointestinal tract. About $20 \%$ were accidental poisoning, and suicidal is approximately $70 \%$, with $30 \%$ of the cases are with fatal outcome ${ }^{10}$. More studies evaluating the risk of diabetes with OP exposure were conducted in other settings but studies related to pesticide applicator occupation are very less. Recent studies have evidenced the pesticides exposure and risk of diabetes. The study on self-reported diabetes and exposure to Organochlorine pesticide exposure revealed that higher level of OC concentration had been associated with a higher prevalence of diabetes ${ }^{11}$. This study particularly focused on the prevalence of diabetes among farmers community to find out the basic link between farming work and diabetes. In this view, the current study was carried out to study the incidence of diabetes among the pesticide applicators of the selected population.

\section{Method}

The study was conducted in the district of Theni, with 102 pesticide applicators. The study was started in 2017 December and completed in March 2018. At enrollment, lifetime exposure to OP pesticides was stated by participants. All participants were informed about the purpose of the study, and their written informed consents were obtained.

\subsection{Questionnaire Assessment}

By using the relevant questionnaire, all participants were asked about the diabetic and exposure to pesticides. It consists of demographic profile, diabetic profile, anthropometric measurements, occupational profile, etc.

\subsection{Health Assessment}

All the participants were undergone for clinical examinations followed by height, weight, and BMI. BMI was calculated as weight $(\mathrm{Kg})$ divided by height (in meter square) and was classified according to WHO classification. Blood pressure was measured in a sitting position and more than $120 / 80 \mathrm{mmHg}$ considered as elevated blood pressure.

\subsection{Blood Collection}

A blood sample of $2 \mathrm{ml}$ was collected in Ethylenediaminetetraacetic acid (EDTA) coated tube from each of the participants. The refrigerated samples were stored in -20 Celsius and shifted to a laboratory for analysis. All the 102 samples ID were manual to avoid personal details.

\section{4 $\mathrm{HbAlc}$}

For all 102 participants, diabetic status was confirmed by $\mathrm{HbAlc}$ analysis in whole blood by fully automated high-performance liquid chromatography (HPLC) using Biorad variant II turbo NGSP certified. Diabetic was defined as either by medication or having a history of diabetes. Clinically, Alc > 6.5\% was considered as diabetic.

\subsection{Statistical Analysis}

Statistical analysis was carried by using R studio software. Descriptive statistics were carried out for general characteristics. Chi-square test and $\mathrm{t}$ - statistics were followed for further analysis and $\mathrm{p}>0.05$ was considered as significant level with 95 \% Confidence interval (CI).

\section{Result}

Prevalence of T2DM was found to be 39(38.24\%) among which only $9(10.47 \%)$ were found to be from the family history of a person having diabetes. From the surveyed population, it was found that blood pressure, smoking habit, alcohol drinking were noticeably high with 34 (33.33\%), 59(57.84\%), 45(44.12\%), respectively. It was also found that among the study population cardiac problem was low 3(2.94\%) and other medical illnesses were found to be 19(18.63\%) [Table1].

Among the study population cited in Table 2, it was observed that the mean $\pm S D$ of age was $45.49 \pm 8.98$. On the other hand, the year of experience in handling pesticide among participants was found to be 18 years approximately. Table 3 shows the variables among diabetic and non-diabetic participants. Mean age of diabetic participants was $47.44 \pm 8.99$ and non-diabetic was $44.51 \pm 8.87$ and was found to be non-significant $(\mathrm{p}=0.124)$. Other 
variables like systolic/diastolic, blood pressure BMI and occupational experience with pesticide application were also found to be not statistically significant.

Table 1. Characteristics of the surveyed population

\begin{tabular}{|l|l|}
\hline Variables & Frequency (\%) \\
\hline Diabetes & $39(38.24 \%)$ \\
\hline The family history of DM2 & $9(10.47 \%)$ \\
\hline Blood Pressure & $34(33.33 \%)$ \\
\hline Alcohol drinking & $59(57.84 \%)$ \\
\hline Smoking habits & $45(44.12 \%)$ \\
\hline Tobacco chewing & $4(3.92 \%)$ \\
\hline Cardiac problem & $3(2.94 \%)$ \\
\hline Other medical illness & $19(18.63 \%)$ \\
\hline & \\
\hline
\end{tabular}

Table 2. Quantitative analysis Among Surveyed Population

\begin{tabular}{|l|l|l|l|}
\hline Variables & Mean \pm SD & Min & Max \\
\hline Age $(\mathrm{N}=102)$ & $45.49 \pm 8.98$ & 29 & 65 \\
\hline Year of experience $(\mathrm{N}=102)$ & $18.23 \pm 9.6$ & 2 & 40 \\
\hline
\end{tabular}

Table 4 shows that none of the risk factors other than alcohol consumption $\mathrm{p}=(0.001)$ were found to be statistically significant.

\section{Discussion}

For the past few decades, there was a scientific link between exposure to synthetic chemicals and a wide variety of diseases, including endocrine disturbances, reproductive tract disorders and neurobehavioral diseases $\frac{12}{}$. In our study, the prevalence of T2DM among occupational OP applicators in the rural population was revealed. Environmental and occupational exposure to pesticides is reported in human studies $\frac{13}{}$. Few animal and human studies report an association between pesticide exposure and the development of insulin resistance and $\mathrm{T}_{2} \mathrm{DM}^{14}$. In this study, the overall prevalence of diabetes among OP pesticide applicators were 39 (38.24\%) and only $9(10.47 \%)$ were found to be from the family history of diabetes. Similarly, a study reported the risk of diabetes mellitus among the rural population were $24.6 \%$ in the high pesticide exposure group ${ }^{7}$. Among DM and nonDM participants the mean age has no influential effect to develop diabetes. Consistently, a study conducted to assess the risk of diabetes, revealed age in each category was not significant $(P=0.99)^{1}$. In case of risk factors for diabetic and non-diabetic, BMI among diabetic patients was found to influence the risk of diabetes $(\mathrm{P}=0.063)$. Few in vivo studies have reported weight gain in mice for chlorpyrifos exposure ${ }^{15}$. In this study, the year of experience in pesticide application did not show a significant effect in diabetes outcome $(\mathrm{p}=0.218)$. Study revealed that there is no significant between the number of years using the insecticides and diabetic outcome. (add reference)

Table 3. Variables among diabetic and Non-diabetic

\begin{tabular}{|l|l|l|l|}
\hline Variables & Group & Mean \pm SD & P.value \\
\hline \multirow{2}{*}{ Age } & Non-Diabetic & $44.51 \pm 8.87$ & \multirow{2}{*}{0.124} \\
\cline { 2 - 3 } & Diabetic & $47.44 \pm 8.99$ & \\
\hline \multirow{2}{*}{ systolic } & Non-Diabetic & $124.85 \pm 10.99$ & \multirow{2}{*}{0.226} \\
\cline { 2 - 3 } & Diabetic & $127.94 \pm 12.5$ & \\
\hline diastolic & Non-Diabetic & $82.06 \pm 5.05$ & \multirow{2}{*}{1} \\
\cline { 2 - 3 } & Diabetic & $82.06 \pm 4.79$ & \\
\hline \multirow{2}{*}{$\begin{array}{l}\text { Year } \\
\text { of.experience }\end{array}$} & Non-Diabetic & $17.35 \pm 9.12$ & \multirow{2}{*}{0.218} \\
\cline { 2 - 3 } & Diabetic & $19.97 \pm 10.43$ & \multirow{2}{*}{0.063} \\
\hline BMI & Non-Diabetic & $25.84 \pm 4.22$ & \\
\cline { 2 - 3 } & Diabetic & $24.12 \pm 4.4$ & \\
\hline
\end{tabular}

Table 4. Qualitative risk factors among Diabetic

\begin{tabular}{|c|c|c|c|}
\hline Variables & Levels & Diabetic & P.value \\
\hline \multirow{2}{*}{$\begin{array}{l}\text { Family.histroy. } \\
\text { of.Dm2 }\end{array}$} & No & $25(32.5)$ & \multirow[t]{2}{*}{0.729} \\
\hline & Yes & $4(44.4)$ & \\
\hline \multirow[t]{2}{*}{ Blood pressure } & No & $22(32.4)$ & \multirow[t]{2}{*}{0.941} \\
\hline & Yes & $12(35.3)$ & \\
\hline \multirow[t]{2}{*}{ Alcohol consumption } & No & $6(14)$ & \multirow[t]{2}{*}{$0.001^{\star *}$} \\
\hline & Yes & $28(47.5)$ & \\
\hline \multirow[t]{2}{*}{ Smoking habit } & No & $15(26.3)$ & \multirow[t]{2}{*}{0.139} \\
\hline & Yes & $19(42.2)$ & \\
\hline \multirow[t]{4}{*}{ BMI } & UnderWt & $3(50)$ & \multirow[t]{4}{*}{0.659} \\
\hline & Normal & $16(35.6)$ & \\
\hline & OverWt & $11(32.4)$ & \\
\hline & Obese & $4(23.5)$ & \\
\hline
\end{tabular}

Among independent risk factors, only alcohol consumption was found to be statistically significant $(\mathrm{p}=$ 
$\left.0.001^{\star}\right)$. In a prospective study, they found a strong inverse association between alcohol consumption and risk of diabetes in cigarette smoking, alcohol abuse ${ }^{\frac{16}{6}}$. Our result raises the question whether the occupation plays the major role are not it may be one of the risk factors, but other confounders also play pathogenesis in diabetes.

In agricultural occupation, the type of exposure may vary related to their work when compared to minimal exposure group, and pesticide applicators have more exposure compared to other workers. In a large prospective agricultural health investigation of incident diabetes in licensed applicators, the risk of diabetes prevalence increased with organophosphate pesticides. There are numerous limitations to our study. The obtained data was skewed with higher age baseline and predominantly male gender was observed in high exposure group. In addition, care was taken to some extent using stratified analysis. Unorganized age classification was also observed where many participants age was rounded off when interviewed. However, the study feels that this was non-differential misclassification as participants in the entire study exhibited this behavior. It is evident that pesticides may influence the increased risk of diabetes in these population. People in the agricultural occupation are more prone to the harmful effects of pesticides and diabetic outcome.

\section{Conclusion}

Our study results show the higher risk of diabetes incidence among OP pesticide applicators. The outcomes supported the existing literature that pesticide exposure increases the peril of diabetes. In future research better study design and sample size will improve the results. Results of the study may attract policymakers to develop a control mechanism against pesticide-exposed agricultural population. The variance is deliberated to be understandable by the subject discrepancy regarding safety practices, health background, and nutritional status. It is essential to note that population choice and recall bias tend to obscure the actual relationship between pesticides and diabetes. From these observations, it is suggested that additional studies with more sample size and better screening of exposure are warranted to confirm our results and to recognize the specific individual compounds that can result in diabetes. Public institutions should certainly address the problem, and health care practical measures to overcome the dangerous effects of pesticides are urgently needed.

\section{Acknowledgment}

The authors extend their deep sense of gratitude to all volunteers who participated in the study and village panchayat. The authors acknowledge Master Public Health student Mrs. Ezhil Vani and Mrs. Saranya, Sri Ramachandra Institute of Higher Education and Research, Chennai, India for support in data collection process.

\section{References}

1. Juntarawijit C, Juntarawijit Y. Association between diabetes and pesticides: a case-control study among Thai farmers. Environmental Health and Preventive Medicine. 2018; 23(1):3. https://doi.org/10.1186/s12199-018-0692-5 PMid:29374457 PMCid:PMC5787249

2. Kaveeshwar SA, Cornwall J. The current state of diabetes mellitus in India. The Australasian Medical Journal. 2014; 7(1):45. https://doi.org/10.4066/AMJ.2014.1979 PMid:24567766

3. Rathish D, Agampodi S, Jayasumana M, Siribaddana S. From organophosphate poisoning to diabetes mellitus: The incretin effect. Medical Hypotheses. 2016; 91:53-5. https:// doi.org/10.1016/j.mehy.2016.04.002 PMid:27142144

4. Rahimi R, Abdollahi M. A review on the mechanisms involved in hyperglycemia induced by organophosphorus pesticides. Pesticide Biochemistry and Physiology. 2007; 88(2):115-21. https://doi.org/10.1016/j.pestbp.2006.10.003

5. Raafat N, Abass MA, Salem HM. Malathion exposure and insulin resistance among a group of farmers in Al-Sharkia governorate. Clinical Biochemistry. 2012; 45(18):1591-5. https:// doi.org/10.1016/j.clinbiochem.2012.07.108 PMid:22885474

6. Montgomery M, Kamel F, Saldana TM, Alavanja M, Sandler DP. Incident diabetes and pesticide exposure among licensed pesticide applicators: Agricultural Health Study, 1993-2003. American Journal of Epidemiology. 2008; 167(10):1235-46. https://doi.org/10.1093/aje/kwn028 PMid:18343878 PMCid:PMC2832308

7. Swaminathan K, Thangavel G. Pesticides and human diabetes: a pilot project to explore a possible link. Practical Diabetes. 2015; 32(3):111-3. https://doi.org/10.1002/ pdi.1937

8. Ramesh P. Lifetime exposure to agricultural pesticides and incidence of diabetes among pesticide applicators. Biomedicine. 2016; 36(4):1-4.

9. Balali-Mood M, Saber H. Recent advances in the treatment of organophosphorous poisonings. Iranian Journal of Medical Sciences. 2012; 37(2):74.

10. Lutovac M, Popova OV, Jovanovic Z, Berisa H, Kristina R, Ketin S. Management, diagnostic and prognostic significance of acetylcholinesterase as a biomarker of the toxic 
effects of pesticides in people occupationally exposed. Open Access Macedonian Journal of Medical Sciences. 2017; 5(7):1021. https://doi.org/10.3889/oamjms.2017.200

11. Beard J, Sladden T, Morgan G, Berry G, Brooks L, McMichael A. Health impacts of pesticide exposure in a cohort of outdoor workers. Environmental Health Perspectives. 2003; 111(5):724-30. https://doi.org/10.1289/ ehp.5885 PMid:12727601 PMCid:PMC1241482

12. Neel BA, Sargis RM. The paradox of progress: environmental disruption of metabolism and the diabetes epidemic. Diabetes. 2011; 60(7):1838-48. https://doi.org/10.2337/ db11-0153 PMid:21709279 PMCid:PMC3121438

13. Gangemi S, Miozzi E, Teodoro M, Briguglio G, De Luca A, Alibrando. Occupational exposure to pesticides as a possible risk factor for the development of chronic diseases in humans. Molecular Medicine Reports. 2016; 14(5):4475-88. https://doi.org/10.3892/mmr.2016.5817 PMid:27748877 PMCid:PMC5101964

14. Swaminathan K. Pesticides and human diabetes: a link worth exploring? Diabetic Medicine. 2013; 30(11):1268-71. https://doi.org/10.1111/dme.12212 PMid:23587011

15. Liang $Y$, Zhan J, Liu D, Luo M, Han J, Liu X. Organophosphorus pesticide chlorpyrifos intake promotes obesity and insulin resistance through impacting gut and gut microbiota. Microbiome. 2019; 7(1):19. https:// doi.org/10.1186/s40168-019-0635-4 PMid:30744700 PMCid:PMC6371608

16. Rimm EB, Chan J, Stampfer MJ, Colditz GA, Willett WC. Prospective study of cigarette smoking, alcohol use, and the risk of diabetes in men. BMJ. 1995; 310(6979):555-9. https://doi.org/10.1136/bmj.310.6979.555 PMid:7888928 PMCid:PMC2548937 